\title{
ESTUDO COMPARATIVO ENTRE CUSTOS ASSOCIADOS COM A UTILIZAÇÃO DE SISTEMAS MULTIMODAIS DE TRANSPORTES
}

\author{
Simone Tavares Fernandes ${ }^{1}$ \\ Fernando Augusto Silva Marins ${ }^{2}$ \\ Josiane Palma Lima ${ }^{3}$ \\ Renato da Silva Lima ${ }^{4}$
}

\begin{abstract}
Resumo: O objetivo do trabalho foi estudar, através de um estudo de caso, a viabilidade do transporte multimodal quando comparado à opção tradicional do transporte rodoviário no Brasil. $\mathrm{O}$ estudo foi conduzido em uma empresa multinacional do setor de laminados de alumínio, onde foram comparados aspectos gerais de custos para o transporte exclusivamente rodoviário, em caminhões de diferentes capacidades, e o transporte multimodal, em duas alternativas: cabotagem e rodoviário e ferroviário e rodoviário. Os resultados mostraram que, para o caso em questão, os custos do transporte rodoviário ainda são menores quando comparados aos do transporte multimodal. Ainda que isso soe como um contra-senso no que se conhece hoje sobre multimodalidade, isso pode ser explicado por alguns fatores, como custos maiores de estoque e de seguro. Outro fator observado no estudo foram as dificuldades operacionais presentes no transporte multimodal, corroborando o que se encontra na literatura sobre o tema.
\end{abstract}

Palavras-chaves: Custos logísticos; Multimodalidade; Transporte por cabotagem, rodoviário e ferroviário.

\begin{abstract}
The goal of this paper was to study, by means of a case study, the viability of multimodal transport when compared to the traditional road transport mode in Brazil. The study was conducted in a multinational enterprise of the aluminum-rolling sector, where general cost aspects of road transport, considering trucks with different capacities, and two multimodal transport configurations were compared: cabotage and road transport; and road and rail transport. The results have shown that, for this case, the road transport costs are still smaller when compared to the multimodal options. Although this may sound a counter sense to what is known today on multimodality, it can be explained by some factors, such as higher costs associated with stocks and insurance. Another observed factor in the study was the operational difficulties of multimodal transportation, which corroborates what is found in the literature on the subject.
\end{abstract}

Keywords: Logistics Costs; Multimodality, Cabotage, road and rail transport.

\section{INTRODUÇÃO}

O Transporte representa, com sua importância já evidenciada em vários trabalhos e pesquisas na área operacional da logística, em média, 60\% dos custos logísticos, 3,5\% do faturamento e, em alguns casos, mais do que o dobro do lucro.

Sua relevância pode ser medida através de indicadores financeiros (custos, faturamento e lu- cro) e observada com base na qualidade dos serviços com impacto direto no tempo de entrega, na confiabilidade e na segurança dos produtos (Fleury, 2002; Fernandes, 2008),

A decisão pelo modal de transporte (rodoviário; ferroviário; aquaviário; dutoviário e aéreo) depende das características do nível de serviço a ser prestado e dos parâmetros de medida em termos da quilometragem do sistema,

\footnotetext{
1 Novelis do Brasil Ltda., simone.tavares@novelis.com

2 Universidade Estadual Paulista - Faculdade de Engenharia - Campus Guaratinguetá, fmarins@feg.unesp.br

3 Universidade Federal de Itajubá - Instituto de Engenharia de Produção e Gestão, jplima@unifei.edu.br

4 Universidade Federal de Itajubá - Instituto de Engenharia de Produção e Gestão, rslima@unifei.edu.br
} 
volume, receita e natureza da composição do tráfego.

Ainda, é considerado o desempenho de cada modalidade de transporte, relativo a custos fixos e variáveis, velocidade, disponibilidade, capacidade e freqüência. (Nazário et al. (2000), Ferreira \& Alves, 2005).

Nas últimas décadas, observou-se um interesse cada vez maior no tema Transporte Multimodal (ou intermodal, para alguns e em algumas diferentes traduçôes do inglês), nos meios acadêmico, empresarial e governamental.

A importância do tema é inegável, visto que o transporte multimodal pode contribuir para a otimização qualitativa e quantitativa do processo de transporte (Demaria, 2004).

No entanto, o estudo do transportes multimodais no Brasil é relativamente recente, o que resulta em uma certa dificuldade em se assimilar o conceito de multimodalidade e sua importância no desenvolvimento econômico do país.

Ainda é freqüente nas empresas não se considerar a importância das combinaçôes dos modais de transporte que são utilizadas para movimentar os produtos nas cadeias de suprimentos ou nos canais de produção-distribuição.

A maior preocupação se dá em obter o melhor serviço de transporte, que atenda às necessidades logísticas, mas muitas vezes as opçôes de multimodalidade não são consideradas, por dificuldades de implantação, seja por motivos operacionais ou de regulamentação da legislação e tributação.

Numa escala menor, mais operacional, algumas empresas se dispõem a partir para opção da multimodalidade, mas esbarram na falta de informações acerca dos custos envolvidos no processo.

Será que os custos, sabidamente mais baixos, dos sistemas de transportes de maior capacidade, utilizados em maiores percursos (aquaviário e ferroviário), se refletem no custo total de uma operação multimodal, principalmente quando combinados como rodoviário?

Esse foi o ponto de partida para o trabalho, que teve por objetivo estudar a viabilidade do transporte multimodal quando comparado à opção tradicional do transporte rodoviário no Brasil.

Para tanto, foi conduzido em estudo de caso em uma empresa multinacional do setor de laminados de alumínio, comparando-se os custos para três alternativas de transporte.
É importante ressaltar que, apesar das diferentes interpretaçóes no Brasil para os termos multimodalidade e intermodalidade, essa não será uma questão aqui abordada; desse modo a operação conjunta de um sistema rodoviário com o ferroviário ou com a cabotagem, por exemplo, será aqui denominada de transporte multimodal, ainda que não exista a figura de um OTM (Operador de Transporte Multimodal) envolvido no processo.

O trabalho está estruturado da seguinte maneira. Após esta breve introdução são apresentadas, nas seções 2 e 3, algumas considerações relacionadas aos Transportes e a Multimodalidade no Brasil. Na seqüência, na seção 4, apresenta-se o estudo de caso, seguido do estudo das alternativas de transporte na seção 5. Finalmente, são apresentadas as conclusões do trabalho, na seção 6 , seguidas das referências bibliográficas.

\section{MULTIMODALIDADE DE TRANSPORTE NO BRASIL}

De acordo com Ballou (2006), um serviço de transporte é um elenco de características de desempenho comprado a um determinado preço.

Existem diferenças no desempenho entre os modais relativos a custos fixos e variáveis, velocidade, disponibilidade, capacidade e freqüência.

Segundo Nazário et al. (2000), as características operacionais de cada modal podem ser definidas como se segue:

- Velocidade - refere-se ao tempo decorrido de movimentação em uma dada rota, também conhecido como transit time, sendo o modal aéreo o mais rápido de todos;

- Disponibilidade - refere-se à capacidade que um modal tem de atender qualquer par origem/destino de localidades. As transportadoras rodoviárias apresentam a maior disponibilidade, já que conseguem dirigir-se diretamente para os pontos de origem e destino, caracterizando um serviço porta-a-porta;

- Confiabilidade - refere-se à variabilidade potencial das programações de entrega esperadas ou divulgadas. Os dutos, devido ao seu serviço contínuo e à possibi- 
lidade restrita de interferência pelas condições de tempo e de congestionamento, ocupam lugar de destaque neste item;

- Capacidade - refere-se à possibilidade de um modal de transporte lidar com qualquer requisito de transporte, como tamanho e tipo de carga. O transporte realizado via marítima ou fluvial é o mais indicado para esta tarefa;

- Freqüência - está relacionada à quantidade de movimentações programadas. Novamente, os dutos lideram o item freqüência devido ao seu contínuo serviço realizado entre dois pontos.

Considerar um sistema multimodal de transporte implica em utilizar mais de um modal na movimentação de cagas por toda a Cadeia de Suprimentos, agregando as vantagens de cada um em relação aos produtos, questões de segurança, valor agregado e o sistema de transporte mais eficiente.

De acordo com a ANTT - Agência Nacional de Transportes Terrestres (2008), o Transporte Multimodal é aquele que, regido por um único contrato, utiliza duas ou mais modalidades de transporte, desde a origem até o destino, e é executado sob a responsabilidade única de um OTM (Operador de Transporte Multimodal).

O Transporte Multimodal de Cargas compreende, além do transporte em si, os serviços de coleta, unitização, desunitização, movimentação, armazenagem e entrega de carga ao destinatário, bem como a realização dos serviços correlatos que forem contratados entre a origem e o destino, inclusive os de consolidação e desconsolidação documental de cargas.

Várias são as vantagens da utilização do Transporte Multimodal, entre as quais (ANTT, 2006):

- Contratos de compra e venda mais adequados;

- Melhor utilização da capacidade disponível da matriz de transporte;

- Utilização de combinações de modais mais eficientes energeticamente;

- Melhor utilização das tecnologias de informação;

- Ganhos de escala e negociações do transporte;
- Melhor utilização da infra-estrutura para as atividades de apoio, tais como armazenagem e manuseio;

- Aproveitamento da experiência internacional tanto do transporte como dos procedimentos burocráticos e comerciais;

- Redução dos custos indiretos.

\section{PRINCIPAIS ENTRAVES DE IMPLEMENTAÇÃO}

De acordo com Reis et al. (2007), o Brasil possui uma legislação aplicada ao transporte multimodal de cargas, porém existem diversos entraves que impedem a sua aplicabilidade e operacionalização.

Dentre estes entraves encontram-se:

- A contradição da definição de transporte multimodal, onde o conhecimento de transporte de carga para cada modo de transporte deve ser emitido em separado;

- O destino das diversas vias de conhecimento de transporte dos diferentes modos de transporte adotados;

- A inexistência de uma alíquota de ICMS única para o transporte multimodal no País (ANTT, 2006).

Além dos entraves originados pela pouca comunicação entre os diversos agentes envolvidos dentro do sistema de carga multimodal, a infraestrutura disponível também pode influenciar de forma decisiva na utilização de mais de um modal de transporte.

Quando existente e adequada às necessidades, a infraestrutura possibilita integrar de forma favorável à logística das empresas, os serviços prestados pelo setor de transportes.

Os baixos investimentos no sistema ferroviário e no aquaviário vêm prejudicando a produtividade na movimentação de cargas no país, dificultando a reestruturação da matriz de transporte brasileira.

Atualmente, a extensão da malha férrea brasileira é pequena (principalmente, levando-se em conta a extensão continental do Brasil) e parte das linhas existentes está em péssimas condiçôes de tráfego. A rede ferroviária está longe de compor um sistema eficiente e integrado. 
Nos portos, problemas de recursos e de gestão comprometem a velocidade de carga e descarga, causando grandes esperas de navios para atracação, congestionamentos, longas filas de veículos e enormes prejuízos financeiros (Lima, 2007a).

Como os demais modais de transporte, aeroviário e dutoviário, têm pouca utilização, a matriz de transportes brasileira é totalmente baseada no transporte rodoviário (aproximadamente $60 \%)$.

\section{A LEGISLAÇÃO APLICADA AO TRANSPORTE MULTIMODAL DE CARGAS}

O funcionamento do sistema multimodal de carga é viabilizado pelo sistema institucional (organizações públicas e privadas) do transporte de carga através de normas, recursos financeiros, equipamentos e instalações (RELATÓRIO ANTT, 2006).

As organizações participam dos processos de planejamento, que são comandados pelos diferentes níveis de atuação político-administrativa de governo, União, Estados e Municípios, viabilizando o funcionamento das atividades de carga no sistema urbano, regional e federal (Reis et al., 2007).

Para o sistema institucional funcionar adequadamente é necessário que as instituições e agentes públicos e privados (Ministérios, Agências federais, estaduais e municipais, Empresas de transportes) tenham seu papel definido, desempenhem-no com efetividade, tenham capacidade de influenciar e normalizar dentro do limite de suas competências e tenham adquirido visibilidade entre seus elos institucionais.

Por outro lado, cada agente como parte integrante de um sistema maior, precisa atuar de forma integrada, coordenada e reciprocamente complementar.

Nunes e Fonseca (2006) comentam que no contexto internacional, há vários anos, organismos internacionais intensificam esforços para ratificar uma legislação uniforme para o transporte multimodal no âmbito internacional.

Pouco conseguiu se avançar, ficando essa uniformidade restrita aos blocos econômicos que ratificaram tratados com o intuito de instituírem a multimodalidade em seus territórios, como por exemplo, o "Acordo de Ouro Preto" firmado entre os países membros do MERCOSUL, em 1994.

O Operador de Transporte Multimodal (OTM) é a principal pessoa jurídica contratada para efetuar o serviço multimodal no transporte de cargas desde a origem até o destino final, sejam estes nacionais ou internacionais, quer por meios próprios ou por intermédio de terceiros.

O contrato de transporte é celebrado entre o expedidor da carga e o OTM, podendo ser negociável ou não, a critério deste último, e regerá todos os atos envolvendo o transporte da carga, desde sua origem até o destino.

Uma vez celebrado o contrato, sua eficácia tem início a partir da emissão do documento que o evidencia chamado de Conhecimento de Transporte Multimodal de Carga - CTMC, bem como, do recebimento da carga pelo OTM.

O modelo do CTMC, definido para o caso brasileiro, foi idealizado pelo Conselho Nacional de Política Fazendária - CONFAZ, no Ajuste SINIEF (Sistema Nacional Integrado de Informações Econômico-Fiscais) no 6 de 2003.

O OTM tem enfrentado problemas para sua efetivação, isso porque a legislação brasileira não conseguiu se adequar às normas internas e internacionais vigentes, principalmente no que se refere ao Ajuste SINIEF 06 de 2003 (Reis et al., 2007).

Ocorre, portanto, que, apesar de regulamentado, o CTMC não tem sido reconhecido. Isso se deve a uma soma de fatores que incidem principalmente sobre o conflito entre legislações.

Existem vários impostos e contribuiçôes que incidem sobre o serviço de transporte de carga no país. A incidência dos impostos na operação de transporte varia de acordo com o produto, modo de transporte, localidade, atividade e especialidade da empresa, trajeto, dentre outros.

No Brasil, de todos os tributos incidentes sobre o transporte de cargas, o ICMS é o mais representativo. A principal característica do ICMS é a predominância do princípio da origem, ou seja, a maior parte da arrecadação desse imposto é recolhida pelo Estado produtor.

O ICMS é cobrado no início do transporte por uma alíquota determinada que incida sobre o valor total da mercadoria a ser transportada (RELATÓRIO ANTT, 2006)

Reis et al. (2007) comentam que os entraves tributários possuem uma questão política e legis- 
lativa. As diferenças de alíquotas ocorrem tanto para os modos de transporte, como também para os estados e têm as suas definições no poder legislativo e nas secretarias de fazenda dos estados.

A inexistência de uma alíquota do ICMS para o Transporte Multimodal de Cargas também é um impedimento para o seu funcionamento.

Entretanto, a questão tributária não é um entrave exclusivo do transporte multimodal, pois o tema representa um entrave para todos os setores da economia brasileira.

\section{A INFRAESTRUTURA DE TRANSPORTES NO BRASIL}

A gestão da infra-estrutura de transportes no Brasil é de responsabilidade dos governos federal, estadual e municipal e cabe a eles proporcionar as facilidades necessárias para que os diferentes modos de transporte operem com eficiência.

Por outro lado, as atividades dos agentes públicos e privados incidem, principalmente, na responsabilidade do processo de planejamento $\&$ gestão dos transportes de suas regiōes e na gestão dos investimentos sob seu controle. Estes agentes devem se responsabilizar por investimentos que, na maioria das vezes, são feitos em infra-estrutura física, envolvendo: estradas, hidrovias, portos, aeroportos e sistemas de trânsito nas áreas urbanas, conforme as necessidades de cada região (Reis et al., 2007).

Devido ao baixo nível de investimentos verificados nos últimos anos com relação à conservação, ampliação e integração dos sistemas de transporte no Brasil, as alternativas modais e multimodais são pouco utilizadas (Nazário et al., 2000).

Segundo Hijjar (2008), o Brasil é um país fortemente voltado para o uso do modal rodoviário, conseqüência das baixas restrições para a operação e dos longos anos de priorização deste modal nos restritos investimentos do governo.

Sendo assim, as rodovias constituem a infraestrutura fundamental para o desenvolvimento global do país.

De acordo com Lima (2007b), durante muitos anos, a maior preocupação referente à relação direta "crescimento econômico e rede de transportes" estava caracterizada pelo aumento em extensão da malha viária dos países em desenvolvimento.
À medida que se passa de uma fase de construção da rede satisfazendo as necessidades, para uma fase essencialmente de conservação da rede existente, o domínio da conservação da qualidade dos pavimentos passará a constituir a atividade mais importante, tendo em conta a relação entre o estado da rede e a qualidade do serviço oferecido ao usuário.

Deve-se enfatizar que as más condições do pavimento e o volume de tráfego elevado comprometem a qualidade da viagem, a depreciação dos veículos e aumenta o risco de acidentes e roubo de cargas.

Por outro lado, a extensão da malha férrea brasileira é pequena e parte das linhas existentes também está em péssimas condições de tráfego. A rede ferroviária está longe de compor um sistema eficiente e integrado.

Nos portos, problemas de recursos e de gestão comprometem a velocidade de carga e descarga, causando grandes esperas de navios para atracação, congestionamentos, longas filas de veículos e enormes prejuízos financeiros (Lima, 2007a).

Nos últimos 10 anos, enquanto o PIB brasileiro cresceu $32 \%$, as exportaçôes totais cresceram $136 \%$, ritmo quatro vezes superior àquele indicador. De acordo com Resende (2006), dentro do processo de crescimento das exportações, houve transformações na sua composição que afetam diferenciadamente o setor de transporte.

Destaca-se, entretanto, o aumento de exportação de subsetores, como o de agronegócios (soja, açúcar, celulose, cargas frigorificadas, carnes e outras proteínas animais, frutas frescas e processadas), veículos e autopeças, produtos eletrônicos e de tecnologia de informação.

O crescimento e as transformações estruturais e espaciais por que vem passando a economia brasileira, o que tende a se acelerar nos próximos anos, já estão tendo implicações diretas no setor de transporte, criando necessidades de adaptaçóes e aparelhamento do mesmo, sobretudo do modal ferroviário e de cabotagem.

Existem pontos de estrangulamento de transportes, quando ocorre a inexistência da infraestrutura necessária. Há consenso sobre a necessidade de se elevar o volume de cargas transportadas por cabotagem no Brasil.

O transporte de granéis sólidos e líquidos por navios não tem sofrido a concorrência direta do modal rodoviário, pois são cargas de grande 
volume e/ou baixo valor, operadas em terminais portuários especializados (na maioria privativos) normalmente conectados a redes ferroviárias ou dutoviárias, havendo, muitas vezes, a integração física entre o porto e a indústria.

As empresas proprietárias das cargas, de um modo geral, dominam toda a cadeia logística de produção e de distribuição, o que explica o dinamismo desse segmento (Informe BNDES, 2002).

O mesmo não ocorre com o segmento de carga geral, que compreende basicamente produtos industriais. As plantas produtivas estão localizadas de maneira dispersa pelo país, a movimentação dos produtos é realizada em terminais portuários públicos e as cargas possuem maior valor e menor volume.

As empresas de transporte realizam apenas a movimentação de cargas ponto a ponto, não possuindo capacidade para oferecer serviços de logística.

Cargas com origem e destino dispersos, inexistência de centros de consolidação e despacho, dificuldades operacionais e legais para realização de transporte multimodal, falta de navios especializados e altos custos portuários explicam a pouca utilização da cabotagem para carga geral.

\section{ESTUDO DE CASO}

De modo a ilustrar um caso prático sobre a escolha ou não da multimodalidade no setor empresarial brasileiro, foi conduzido um estudo de caso procurando-se avaliar as decisóes tomadas baseadas em custos de operação e disponibilidade de infraestrutura.

A empresa estudada é a Novelis do Brasil Ltda, multinacional do setor de laminados de alumínio, especializada na produção de chapas e folhas de alumínio. Está presente em 11 países e com 37 plantas (Fernandes, 2008), trabalhando há cerca de 60 anos no mercado nacional, com operações de alumínio primário, produtos químicos e autogeração de energia.

Suas quatro plantas estão localizadas nas cidades de Pindamonhangaba (SP), Santo André (SP), Ouro Preto (MG) e Aratu (BA). O processo de transporte da empresa, que será aqui analisado, movimenta produtos entre as regióes sudeste e nordeste, entre duas plantas da empresa, um cliente e um fornecedor.
Os produtos transportados são placas, bobinas de alumínio e coque (matéria-prima na produção de alumínio). A Figura 1 apresenta a localização geográfica dos envolvidos, a saber:

- Planta Aratu, localizada no estado da Bahia, a $30 \mathrm{~km}$ do porto de Salvador. Produz placas de alumínio;

- Planta Pindamonhangaba, localizada no estado de São Paulo, próxima à Dutra no eixo entre Rio e São Paulo. Produz bobinas de alumínio;

- Cliente Camaçari, localizado no estado da Bahia, próximo ao porto de Salvador. Produz as latas de alumínio;

- Fornecedor Cubatão, localizado no estado de São Paulo, próximo ao porto de Santos. Produz o produto coque de petróleo;

Uma das características do processo é que todos os produtos envolvidos são entregues diariamente, e possuem características, dimensões, formas de carregamento, descarregamento e armazenagem diferentes.

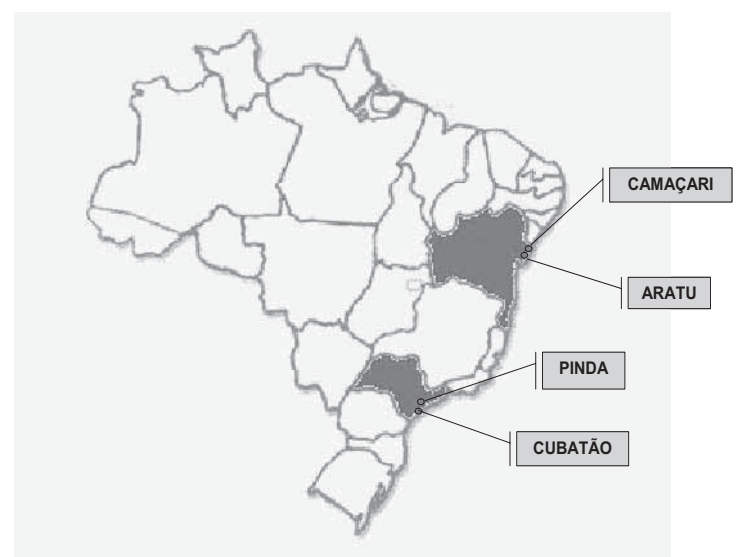

\section{Figura 1: Localização dos Envolvidos no Processo de Transporte}

\section{CARACTERÍSTICAS DOS PRODUTOS TRANSPORTADOS}

Existem três tipos de produtos envolvidos no processo logístico de transporte: placas de alumínio, bobinas de alumínio e o coque, conforme apresentados na Figura 2a, Figura 2b e Figura 2c, respectivamente.

As Placas de Alumínio, conforme a Figura $2 a$, pesam de 6,5 a 14 toneladas, tem forma retangular, as dimensões variam na largura de 1.050 
a 1.850 milímetros; no comprimento de 3.650 a 5.500 milímetros; e medem 610 milímetros de altura.

São movimentadas nas fábricas com ponte rolante, não é um produto que requer muitos cuidados de manuseio e transporte. $\mathrm{O}$ transporte deste produto tem origem na planta de Aratu e destino na planta de Pindamonhangaba;

As Bobinas de Alumínio, apresentadas na Figura $2 b$ têm peso médio de 9,2 toneladas, forma cilíndrica, diâmetro de 1.750 milímetros e comprimento de 1.525 milímetros.

São movimentadas, nas fábricas, por meio de empilhadeiras; é um produto que não pode ter marcas de garfo de empilhadeira e nem manchas provenientes de umidade.

$\mathrm{O}$ transporte deste produto tem origem em Pindamonhangaba e destino na planta de Camaçari (cliente).

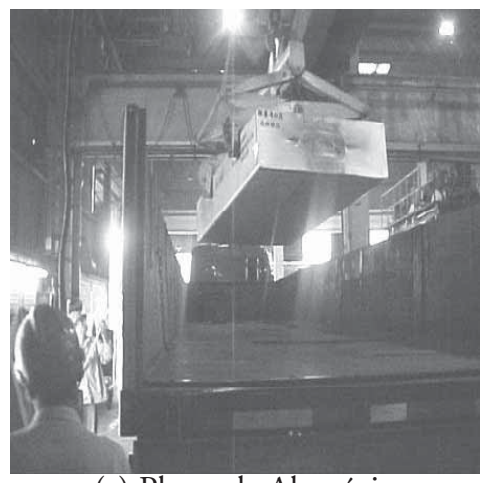

(a) Placas de Alumínio

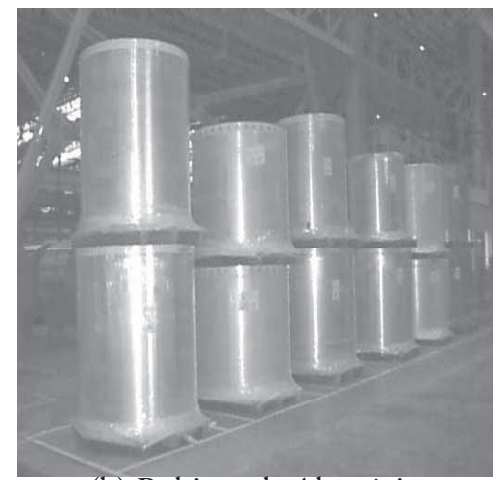

(b) Bobinas de Alumínio

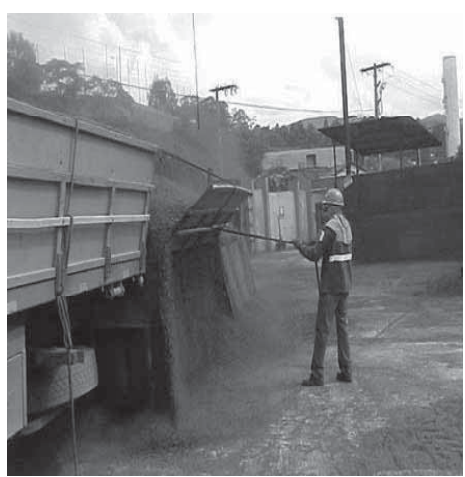

(c) Coque

Figura 2: Produtos Envolvidos no Processo de Transporte

O Coque, conforme apresentado na Figura 2c, é um produto a granel e matéria-prima na manufatura de anodos para produção de alumínio. É carregado em caminhóes através de silos e descarregado no destino com o uso de caminhóes basculantes ou equipamento chamado de varredeiras. É um produto que não requer grandes cuidados de manuseio e transporte. $\mathrm{O}$ transporte deste produto tem origem em Cubatão e destino na planta de Aratu.

O processo de transporte estudado compreende: o transporte dos produtos; o carregamento e descarregamento dos mesmos; e o tempo de portaria das plantas envolvidas. As portarias analisadas realizam as atividades de recebimento, pesagem dos veículos vazios e autorização de entrada. Após entrada na planta e carregamento dos veículos, os mesmos retornam à portaria para nova pesagem, autorização de saída e emissão de nota fiscal. Todo o processo de transporte é feito com diversas transportadoras, sem sinergia entre elas. A estrutura simplificada do processo de transporte é apresentada na Tabela 1 e na Figura 3, onde estão mostrados os trechos de transporte rodoviário ou multimodal, desde a origem até o destino, produto e volume mensal de toneladas embarca- das por trecho, cada qual sendo gerenciado independentemente pelas empresas responsáveis pela contratação do frete.

\section{Tabela 1: Origem e Destino dos Produtos Transportados}

\begin{tabular}{|c|c|c|c|}
\hline Origem & Destino & Produto & ton/mês \\
\hline Aratu-BA & Pinda-SP & Placas & 5898 \\
\hline Pinda-SP & Camaçari-BA & Bobinas & 1200 \\
\hline Cubatão-SP & Aratu-BA & Coque & 1498 \\
\hline
\end{tabular}

\begin{tabular}{ccc|}
\hline $\begin{array}{c}\text { Planta Empresa } \\
\text { Aratu }\end{array}$ & $\Rightarrow$ & $\begin{array}{c}\text { Planta Empresa } \\
\text { Pinda }\end{array}$ \\
\hline $\begin{array}{c}\text { Planta Empresa } \\
\text { Pinda }\end{array}$ & $\Rightarrow$ & $\begin{array}{c}\text { Planta Cliente } \\
\text { Camaçari }\end{array}$ \\
\hline $\begin{array}{c}\text { Planta Fornecedor } \\
\text { Cubatão }\end{array}$ & $\Rightarrow$ & $\begin{array}{c}\text { Planta Empresa } \\
\text { Aratu }\end{array}$ \\
\hline
\end{tabular}

Figura 3: Transporte rodoviário ou multimodal 


\section{ESTUDO DAS ALTERNATIVAS DE TRANSPORTES}

Foi analisada a viabilidade de utilização do modal rodoviário, da multimodalidade com o uso dos modais rodoviário, ferroviário e cabotagem.

$\mathrm{Na}$ multimodalidade consideraram-se operaçōes, nas quais são utilizadas dois ou mais modais, no transporte das mercadorias ou produtos. As operaçóes logísticas porta-a-porta, ou em inglês door to door, compreendem a retirada da mercadoria na planta de origem, até a entrega na planta do cliente.

De acordo com estes conceitos, os operadores logísticos utilizam a cabotagem e a ferrovia associadas ao transporte rodoviário. $\mathrm{O}$ modo rodoviário é utilizado para transportar os produtos nos trechos iniciais e finais do trajeto, em uma operação porta a porta, o que também é denominado de pontas rodoviárias.
O primeiro processo analisado foi o transporte de placas entre as plantas de Aratu e Pindamonhangaba. Neste processo foram analisados o transporte rodoviário com veículos de capacidade de 27, 30 e 40 toneladas e os multimodais: cabotagem com rodoviário; e ferrovia com rodoviário, em contêineres de 30 toneladas.

$\mathrm{Na}$ Tabela 2 apresenta-se a avaliação das alternativas por meio dos custos envolvidos em cada tipo transporte. As variáveis analisadas foram:

- Os preços dos fretes representados em u.m. - unidades monetárias, pois os valores reais foram multiplicados por uma constante para preservar dados confidenciais da empresa, sem perder a proporcionalidade entre eles;

- A capacidade de ocupação dos caminhões ou contêineres (GU);

- O custo do seguro da mercadoria para cada tipo de transporte;

Tabela 2: Avaliação dos custos de transporte Aratu - Pindamonhangaba

\begin{tabular}{|c|c|c|c|c|c|c|}
\hline \multirow{2}{*}{\multicolumn{2}{|c|}{ ARATU - PINDAMONHANGABA }} & \multirow{2}{*}{\multicolumn{3}{|c|}{ RODOVIÁRIO }} & \multicolumn{2}{|c|}{ MULTIMODAL } \\
\hline & & & & & \multirow{2}{*}{$\begin{array}{l}\text { CABOTAGEM E } \\
\text { RODOVIÁRIO } \\
\text { CNTR } 30 \text { ton }\end{array}$} & \multirow{3}{*}{$\begin{array}{c}\text { FERROVIÁRIO E } \\
\text { RODOVIÁRIO } \\
\text { CNTR } 30 \text { ton } \\
961,95\end{array}$} \\
\hline Capacidade Equipa & & \multirow{2}{*}{$\begin{array}{l}27 \text { ton } \\
701,90\end{array}$} & \multirow{2}{*}{$\begin{array}{l}30 \text { ton } \\
809,94\end{array}$} & \multirow{2}{*}{$\begin{array}{c}40 \text { ton } \\
1080,55\end{array}$} & & \\
\hline Frete & u.m. & & & & 850,95 & \\
\hline GU & $\%$ & 87,80 & 97,30 & 89,90 & 86,70 & 86,70 \\
\hline Frete/GU & u.m. & 799,43 & 832,41 & 1201,95 & 981,87 & 1109,94 \\
\hline Custo por tonelada & u.m./ton & 29,61 & 27,75 & 30,05 & 32,73 & 37,00 \\
\hline Custo Seguro & u.m./ton & 5,81 & 5,81 & 5,81 & 9,30 & 4,65 \\
\hline Custo Financeiro & u.m./ton & 0,67 & 0,63 & 0,67 & 0,00 & 0,00 \\
\hline Cuto de Estoque & u.m./ton & 0,00 & 0,00 & 0,00 & 10,43 & 10,43 \\
\hline Custo Final & u.m./ton & 36,09 & 34,19 & 36,54 & 52,46 & 41,65 \\
\hline
\end{tabular}

- O custo financeiro que alguns transportadores cobram nos preços devido aos prazos de pagamento;

- O custo incremental do estoque em caso de mudança do rodoviário para outros modais.

O custo transportado por tonelada considerava o preço do frete e grau de ocupação dos caminhões ou contêineres. Sobre este preço por tonelada acrescentou-se o seguro da mercadoria, custo financeiro e o custo do aumento do estoque.

Após estas comparações verificou-se que o melhor custo final para o transporte da mercadoria placa foi o modal rodoviário. Os outros mo- dais, apesar do preço competitivo do frete, apresentaram algumas limitações que se refletiram no custo final do transporte.

O sistema multimodal por cabotagem e rodovias apresentou o seguro da mercadoria na cabotagem $(0,2 \%$ sobre o valor da mercadoria) muito menos atrativo que o rodoviário $(0,08 \%$ sobre o valor da mercadoria).

Este seguro mais alto deve-se ao fato dos transportes multimodais necessitarem do transporte rodoviário nas pontas do trajeto; o que implica em absorver o seguro das transportadoras, numa operação porta-a-porta.

Outro aspecto observado refere-se ao volume incremental do estoque devido ao aumento no 
tempo de trânsito da mercadoria de cinco dias no rodoviário, para sete dias na cabotagem e freqüência semanal dos navios.

O sistema multimodal por ferrovias e rodovias apresentou o seguro da mercadoria da mesma forma que na cabotagem $(0,10 \%$ ferroviário e $0,08 \%$ rodoviário), o qual tem um alto impacto no custo, devido ao fato do alumínio possuir grande valor de venda.

$\mathrm{O}$ estoque incremental foi outro agravante. Nesse caso o tempo de trânsito era de 10 dias apesar da frequiência diária. O terminal ferroviário mais próximo da planta de Pindamonhangaba, sem necessidade de transbordo do material, localizava-se em Campinas (diferença da dimensão das bitolas em linhas ferroviárias no Brasil), o que exigia um longo trecho rodoviário.

Por conta dessa grande dificuldade operacional, a utilização da combinação multimodal com o ferroviário foi descartada, não chegando sequer a ser considerado nas outras operações (detalhadas a seguir).

Em ambos os casos de multimodalidade, as operaçôes exigiam contêineres open top, ou seja, que permitissem carregar as placas via parte superior dos mesmos, por meio de ponte rolante. Este tipo de contêiner não é utilizado em larga escala no mercado, o que poderia trazer à operação, alguns transtornos.

Frente às limitações dos outros modais, fez-se a opção pelo transporte rodoviário para as placas, cujo custo mostrava-se mais atrativo, e é o modal de maior flexibilidade.

Foram realizadas análises semelhantes ao transporte de bobinas de Pindamonhangaba para Camaçari, e do coque, de Cubatão para Aratu.

No transporte de bobinas, da mesma forma que no transporte das placas, as limitaçōes foram semelhantes entre o modal rodoviário e o multimodal (cabotagem e rodoviário).

Para o transporte das bobinas, os custos entre os diferentes modais ficaram muito próximo uns dos outros, mais ainda assim a decisão da empresa foi utilizar, também, o modal rodoviário. $\mathrm{Na}$ Tabela 3 apresenta-se a análise dos custos. O transporte do coque entre Cubatão e Aratu seguiu a avaliação dos modais conforme Tabela 4 .

Tabela 3: Avaliação dos custos de transporte Pindamonhangaba - Camaçari

\begin{tabular}{llcccc}
\hline \multicolumn{2}{c}{ PINDAMONHANGABA - CAMAÇARI } & \multicolumn{3}{c}{ RODOVIÁRIO } & $\begin{array}{c}\text { MULTIMODAL } \\
\text { CABOTAGEM E } \\
\text { RODOVIÁRIO }\end{array}$ \\
\hline Capacidade Equipamentos & & 27 ton & 30 ton & 40 ton & CNTR 30 ton \\
Frete & u.m. & 941,01 & 1129,22 & 1223,76 & 835,10 \\
GU & $\%$ & 79,00 & 96,00 & 89,00 & 93,30 \\
Frete/GU & u.m. & 1191,16 & 1176,27 & 1375,01 & 894,74 \\
Custo por tonelada & u.m./ton & 44,12 & 39,21 & 34,38 & 29,82 \\
Custo Seguro & u.m./ton & 3,66 & 3,66 & 3,66 & 11,82 \\
Cuto de Estoque & u.m./ton & 0,00 & 0,00 & 0,00 & 3,13 \\
Custo Final & u.m./ton & $\mathbf{4 7 , 7 8}$ & $\mathbf{4 2 , 8 7}$ & $\mathbf{3 8 , 0 4}$ & $\mathbf{4 4 , 7 7}$ \\
\hline
\end{tabular}

Tabela 4: Avaliação dos custos de transporte Cubatão - Aratu

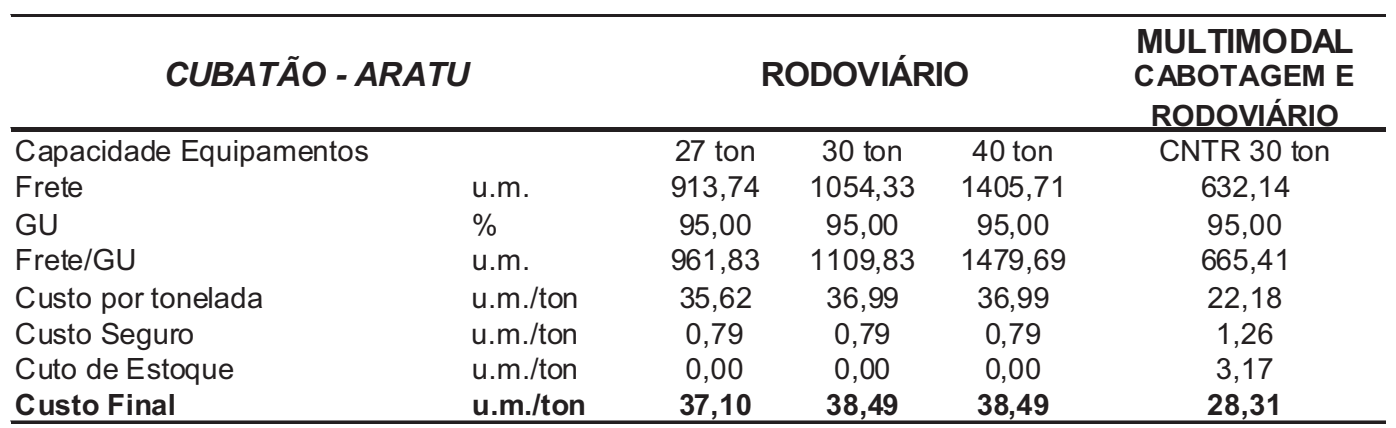


Diferentemente das outras situações, o multimodal cabotagem e rodoviário mostrou-se mais atrativo em termos de custos, apesar das limitações da operação, como por exemplo, o uso de embalagem especial para armazenar o produto dentro dos contêineres e a forma de carregar os mesmos.

A distância entre a planta que fornece o produto coque e o Porto de Santos foi mínima, diminuindo drasticamente o custo da ponta rodoviária até o porto. No entanto, apesar do menor custo do multimodal (cabotagem e rodoviário) para o coque, a empresa optou por buscar sinergia e integração entre as rotas, através da utilização do transporte rodoviário, decisão que será discutida a seguir.

Finalmente, as opções da multimodalidade foram consideradas como caminhos alternativos para a solução do problema.

Entretanto, o modal rodoviário foi escolhido como a melhor alternativa no momento da análise realizada, porque, além da flexibilidade, existia a oportunidade de junção dos volumes embarcados em uma operação casada de transporte, aproveitando os fluxos de produtos, entre as regioes sudeste e nordeste do Brasil.

De forma geral, considerou-se a multimodalidade, uma operação com muitas limitações e restrições.

\section{CONCLUSŌES}

O objetivo do trabalho foi estudar a viabilidade do transporte multimodal quando comparado à opção tradicional do transporte rodoviário no Brasil.

Para tanto, foi conduzido em estudo de caso em uma empresa multinacional do setor de laminados de alumínio, onde foram comparados aspectos gerais de custos para o transporte exclusivamente rodoviário, em caminhōes de diferentes capacidades, com o transporte multimodal, em duas alternativas: cabotagem com rodoviário e ferroviário com rodoviário.

Os resultados para o caso em questão mostraram que os custos de transporte do rodoviário ainda são menores do que a utilização do transporte multimodal.

Ainda que isso soe como um contra-senso, quando comparado a outros recentes estudos so- bre multimodalidade, esse custo maior pode ser explicado por alguns fatores, como:

- Ocorrência de um custo maior de estoque envolvido no processo, decorrente da maior capacidade de carga presente no transporte multimodal, o que requer uma maior consolidação de carga para despacho;

- Custo do seguro mais elevado.

Esses fatores acabam por anular a vantagem que se obtêm no custo de transporte por tonelada, sabidamente mais baixo no transporte multimodal.

Outro fator a se destacar são as dificuldades operacionais observadas no transporte multimodal, corroborando a literatura consultada.

A falta de ferrovias, ou a dificuldade operacional ocasionada por diferentes bitolas, por exemplo, faz com que a atratividade desse modal de transporte ainda seja baixa para muitas empresas, como foi a do caso aqui estudado.

Some-se a isso a grande facilidade e acessibilidade do transporte rodoviário, que acaba por se tornar mais um fator inibidor do transporte multimodal.

Isso também foi observado no estudo de caso, uma vez que a empresa optou por utilizar o transporte rodoviário mesmo em uma situação em que ele teria um custo mais baixo, em nome da flexibilidade e da integração com as outras operações de transporte da empresa.

Por fim, é importante destacar que esse trabalho não teve a pretensão de ser algo conclusivo e sim ilustrativo, uma vez que tratou de apenas uma empresa.

As análises quantitativas, em termos de custo, não podem ser extrapoladas para outras situações e outros tipos de produtos a serem transportados, que podem ter outras combinaçôes de custo.

Ainda assim, situações como as dificuldades operacionais da multimodalidade são fatores marcantes e presentes em praticamente todo o transporte brasileiro de cargas.

\section{AGRADECIMENTOS}

Os autores agradecem ao $\mathrm{CNPq}$ (Conselho Nacional de Desenvolvimento Científico e Tec- 
nológico) e a FAPEMIG (Fundação de Amparo à Pesquisa do Estado de Minas Gerais), pelo apoio financeiro concedido a diversos projetos que subsidiaram o desenvolvimento desse trabalho.

\section{REFERÊNCIAS BIBLIOGRÁFICAS}

ANTT - Agência Nacional de Transporte Terrestres. Transporte Multimodal de Cargas. Disponível em: < http://www.antt.gov.br/carga/multimodal/otm.asp >. Acesso em: 25 Mar, 2008.

BALLOU, R.H. Gerenciamento da Cadeia de Suprimentos/ Logística Empresarial. 5a. Edição. Porto Alegre: Bookman, 2006.

DEMARIA, M. O Operador de Transporte Multimodal como Fator de Otimização Logística. Florianópolis. Dissertação de Mestrado em Engenharia de Produção e Sistemas, UFSC, 2004. 86p.

FERNANDES, S.T. Aplicação do Lean Six Sigma na logística de transporte de produtos de uma indústria metalúrgica. Guaratinguetá. Dissertação de Mestrado em Engenharia Mecânica, UNESP, 136pp. 2008.

FERREIRA, K.A; ALVES, M.R.P.A. Logística e troca eletrônica de informação em empresas automobilísticas e alimentícias. Produção, v. 15, nº 3, pp.434 - 447, Dez, 2005.

HIJJAR, M.F. Preços do Transporte Rodoviário no Brasil. Revista Tecnologística, v.13, no. 147, fev., 2008.

Informe BNDES - Banco Nacional de Desenvolvimento Econômico e Social (2002). Informe de Infra-estrutura. Área de projetos de Infra-estrutura. Disponível em: < http://www.bndes.gov.br/ conhecimento/infra/g7310 .pdf> Acesso em Jul, 2008.

LIMA, J.P. Modelo de decisão para a priorização de vias candidatas às atividades de manutenção e reabilitação de pavimentos. São Carlos. Tese de Doutorado. USP, 167 pp., 2007a.

LIMA, R.F.C. Práticas da gestão do transporte rodoviário de cargas nas empresas (parte 1). Revista Tecnologística, $\mathrm{n}^{\circ}$. 144, pp.66-70, Nov, 2007b.

NAZÁRIO, P.; WANKE, P.; FLEURY, P.F. O papel do transporte na Estratégia Logística. Revista Tecnologística, no. 61, pp.42-47, Dez, 2000.

NUNES, A. O.; FONSECA, A. P. Identificação e Análise à Multimodalidade no Brasil. XX ANPET - Congresso Nacional de Pesquisa e Ensino em Transportes. Brasília, DF. Anais - Panorama Nacional da Pesquisa em Transportes. 2006.

REIS, H.C.G.; FONSECA A. P.; SILVA, E.P. S. Estudo da aplicabilidade do transporte multimodal de cargas no Brasil. XXI ANPET - Congresso Nacional de Pesquisa e Ensino em Transportes. Rio de Janeiro, RJ. Anais - Panorama Nacional da Pesquisa em Transportes, 2007.

Relatório ANTT - Agência Nacional de Transporte Terrestres. Identificação de Entraves Burocráticos e Exigências Legais e Tributárias e Recomendações de Ações de Racionalização para o Desenvolvimento da Multimodalidade no País. Agência Nacional de Transportes Terrestres (ANTT), Universidade de Brasília (UnB), Brasília. 2006.

RESENDE, J.A.N. Logística de transporte e o papel das ferrovias no Brasil Agência Nacional de Transportes Terrestres - ANTT. Disponível em: < http://www.cnt.org.br/> Acesso em julho/2008 